\title{
Synthesis of Ciguatoxin (CTX1B)
}

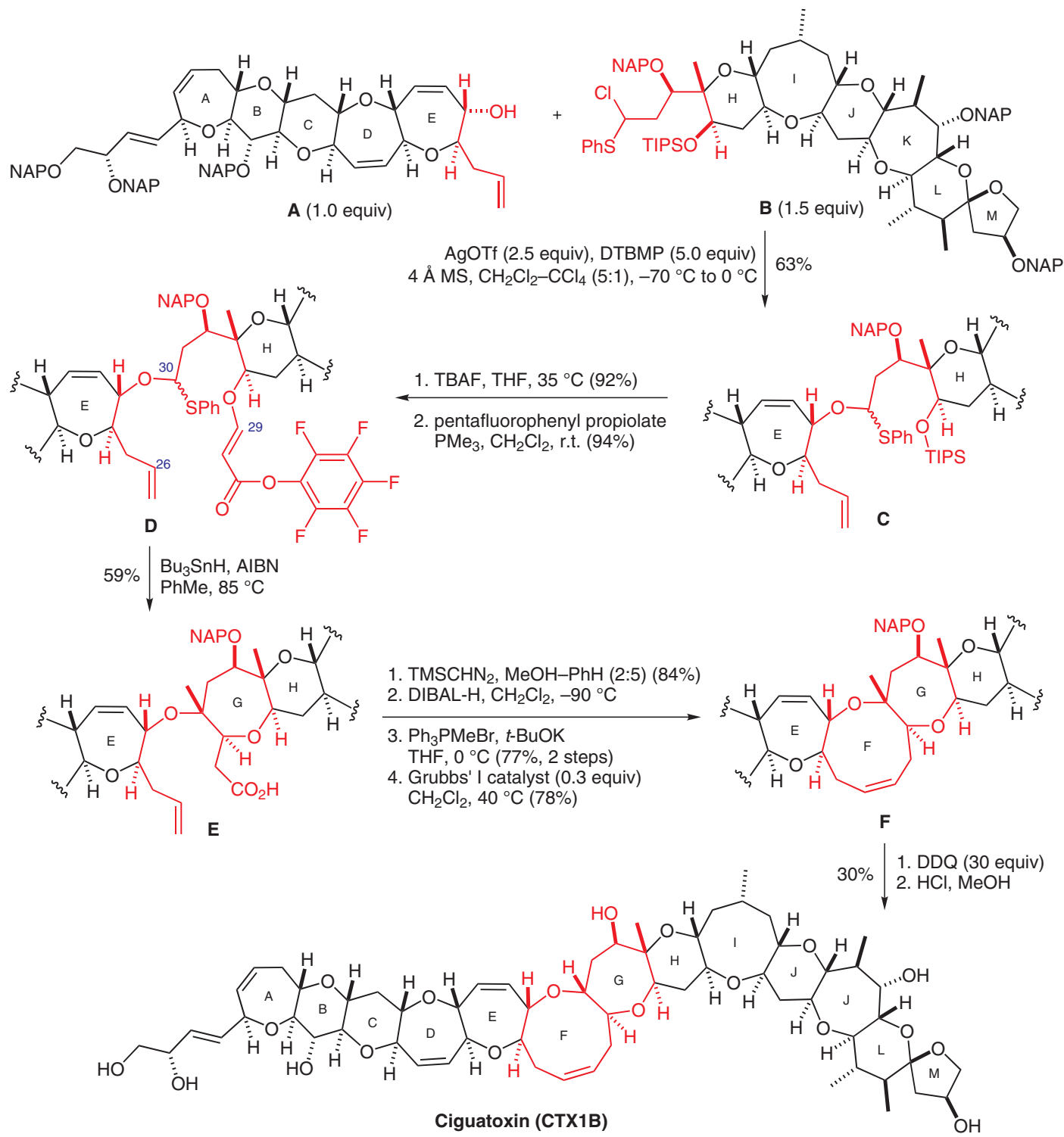

\section{Key words}

radical cyclization

Significance: This awesome synthesis of ciguatoxin features the use of a thioether group to (a) promote linkage of fragments $\mathbf{A}$ and $\mathbf{B}$ via the formation of an O,S-acetal $\mathbf{C}$ and (b) serve as a radical precursor in the cyclization of $\mathbf{D}$ to $\mathbf{E}$.
Comment: The 7-exo-trig cyclization (D to E) of the $\mathrm{C} 30$ radical onto the acrylate moiety at C29 was favored over the 6-exo-trig cyclization onto C26 by using the pentafluorophenyl ester.

SYNFACTS Contributors: Philip Kocienski

Synfacts 2006, 12, 1193-1193 Published online: 22.11.2006

Dol: 10.1055/s-2006-955591; Reg-No.: K13806SF 